\title{
Soul Mate Selection among Adolescents: The Kinetics and Health Perceptions and Interpretations.
}

\author{
S. N. Okoli (M.Sc), C. M. Ugwuegede (Ph.D) and U. N. Igboke (M.Sc)
}

Department of Human Kinetics and Health Education, Enugu State University of Science and Technology (ESUT), Enugu, Nigeria.

Corresponding Author: C. M. Ugwuegede (Ph.D) Emekaugwuegede2016@gmail.com

\begin{abstract}
Soulmate is a brother/sister relationship, practiced and known by many people but just a few especially adolescents understand the exact meaning hence the need to provide adequate information regarding the selection. Adolescents have the tendency to deviate from social norms in search of identity and most often unsure of themselves as most of their experiences rest in the hands of their peer groups. Soulmate comes in form of stranger, healing, wrecking ball, twin and true love soulmates. These are highlighted in the elements of soulmate as one who makes you feel entirely whole, healed, and intact like no piece is missing. Adolescents make selection on the basis of physical attractiveness, economic and social status, age, religion. Finding a true soulmate result in having a feeling of security and protection, falling in love, sharing the same life goals, respect for each other's differences and opinions. However, wrong mate choices could result in social and health consequences such as prostitution, medical problems and suicide. Kinetics and Health strongly emphasize on aesthetics, general wellness including spiritual wellbeing as strong indices of wellness which could be cached on during mate selection. Conclusively, mate selection is a matter of destiny ordered by God but as two loving people who have settled for each other's strength or weakness, the decision is yours. The recommendation among others is that adolescents should be counseled to focus selection of mate on attitude as against physical attributes and made a priority among undergraduate students due to growing cases of rape in Nigeria.
\end{abstract}

Key Words: Soulmate, Adolescent, Kinetics and Health

DOI: $10.7176 / \mathrm{JHMN} / 79-06$

Publication date: August 31st 2020

\section{Introduction}

Mate selection is one of the primary functional responsibilities of all mammals (human beings inclusive) and an important decision to make in the course of growth and development in life. According to online Dictionary report, mate means to join together-that is two entities (objects) being matched. In human beings, it involves a male and a female coming to join together in body and soul as soul mate. Soul mate is a person with whom one has a feeling of deep or natural affinity in form of love, romance, platonic relationships, comfort, intimacy, sexuality, sexual activities, spirituality, compatibility and trust (Patrick, 2012). In current usage, soul mate usually refers to a romantic or platonic partner with the implication of an exclusive life long bond (Springer, 2012). The common connotation here is that soul mate is the strongest bond with another person that one can achieve. A soul mate is a separated entity with whom one has spent many lifetimes as a friend, lover, coworkers or partner, and to whom one is usually drawn to fulfill a specific mission (Mark \& Elizabeth, 2017). It is described as one of many potential spiritual brothers and sisters, even though there may be a great attraction and bond between soul mate. Fundamentally in the intimate sense it could be perceived as a brother/sister relationship although soul mate has great marriage and a great union of hearts.

Soul mate is an act that is practiced and known by many people but just a few especially the adolescents are acquainted by or knows the exact meaning. However, it is an activity that a good number of them are interested and engaged in at all times (Sorul , 2013). Everyone wants to find a soul mate but surprisingly, empathy and kindness towards oneself is the key to becoming wonderful in the act. In that regard, Fulfillment Daily Word Best (2017), in a survey submits that the secret of being a wonderful soul mate is through self compassion but however, regretted that many individuals are unaware of it. This also makes the issue of soul mate an important decision in life and a public health issue. Soul mate is an old as man.

Historically, soul mate has different versions ranging from philosophical to religious and literary dimensions. From the account of the ancient Greek and Egyptian theories, human beings originated in pairs, bound in one body with one original soul but were later split into two due to disrespect to gods. It is reported that the newly separated humans forever wandered the earth in their long lost soul mate to reunite their incomplete souls and become one again (Burbone \& Bralt, 2014). Soul mate from Plato, the great philosopher dated 400BC has its own version thus; "our ancestors once had two heads, four arms and supposedly one soul". They did something to offend a god so that the god punished them by splitting them down the middle resulting in the creation of human, as punishment, we are condemned to spend our lives searching for the other half our soul mates (Burbon \& Brelt, 2014). From the Egyptian and Greek perspective soul mate choice is a product of his lifetime to locate his or her split soul. 
There is however, this other account regarding the origin of sin as recorded in the myth of Aristophanes which has it that from the beginning of creation humans supposedly had neither love for one another nor piety towards the heavenly powers. They were said to be guilty of original sin, who once they sin become human being who were faced with a characteristics moral choice either to achieve wholesomeness through love or to renew their insolence toward the god and run the risk of being diminished further (Singer 1966). This logic was said to have been translated into the Adam and Eve that is "clay" and "Breath" theology regarding the origins of human as passed along the world in Biblical/Quoranic story creation as told in the book of Genesis. These accounts regarding the origin of soul mate are still subject to further verifications. It also points to the fact that soul mate was part and parcel of human creation which ought to be recognized and respected by individuals searching for it.

The search for soul mate is perhaps a compulsory exercise before every human being including adolescents irrespective of age, colour or socio-cultural variations. There are considerable variations regarding soul mate decisions across the globe. In the United States and Russia, ambitions and industriousness of a prospective mate were more important for women than men, presumably because these traits are indicators of reproductive potentials in a man. That is his ability to eventually achieve cultural success (Hatfield \& Sprecher, 2015). British women on the other hand were found to be three times more likely than British men to seek financial security in a prospective partner (Greenlees \& McGrew, 2004). In Asia, Japanese women were three times more likely, than their male counterparts to seek financial security and social status in a prospective longtime partner (9.4\% to $0.3 \%$ ) (Oda, 2011). In Europe world, Hungarian men and women who were 35 years of age or older who married older and more educated men on average had more children were less likely to get divorced. According to the report higher levels of satisfaction was recorded far higher than did women who married younger and/ or less educated men (Bereczkec \& Sanaky's, 2006). In this report, emphasis is on age of the prospective mate. This disposition is supported in Whissel (2006), report which found the same across 25 contemporary romance-novels and six classical novels that have traditionally appealed to women more than men including two stories from the old Testament written 3000 years ago. In these stories the male protagonist is almost always older, socially dominant and wealthy man ultimately marries the woman . To this end, Geary, Idem and Low (2008), submit that marrying a culturally successful man provides the woman with social, psychological and reproductive benefits.

In Nigeria, some degree of variations also exists regarding soul mate selection. In Igbo land, partner selection is technically made by the young woman's kin, but in most cases the parents decision are influenced by their daughter's preference. Usually, these joint decisions are strongly influenced by the amount of landed property made available to her future children. In South-western Nigeria in the time past, parents and families play a significant roles in mate selection for their children so much so that they go as far as negotiating for a life partner whom they believe would be compatible with their children (Ogunjuyigbe \& Adeyemi, 2003). In the South-west experience, the underlying factors range from family history of the intended mates to the intended mate social standing such that issues like health, social economic and moral factors come into play. The process of mate selection among the Yoruba's of South-west Nigeria is clearly influenced by their values for marriage. This rightly explains why they see nothing wrong in parents of a prospective husband introducing their son to a lady they have observed over a period of time to be well behaved and / or industrious as potentials wife. The parents holds the belief that the young man knows little or nothing about the issues of life hence they do marriageable son have what they consider to be the best choice for him (Owagbemi \& Maduawuchi, 2015).

In Hausa land, emphasis is on land and cattle. In this culture, land and cattle are controlled by men and gaining access to these resources has important reproductive consequences for women's reproductive success and maybe contributing to reproductive differentials, given the greater availability of food in the homes of "richer" women and lower incidence illness among them and their offsprings (Borgerhoff, 2008). Generally in Nigeria, in some cases, the parents of the prospective husband can initate the process with the parents of the girl. This move many be kept secret from both prospective mate until both parents have made substantive progress towards the proposed union (Owagbemi \& Maduawuchi 2015). Theses process however, have changed over the years especially with the advents of technology and attending diffusion of cultures across the globe. This also portends some dangers for the prospective adolescents searching for soul-mate.

Adolescent is generally regarded as a stage of experimentation which may also come with crisis. Adolescents are young people who have attained the age of puberty and falls within the age bracket of 11-19 years (WHO, 2015). Youngsters experience generally rests in the hands of peer groups which may influence their choice of mate. Majority of adolescents are constantly in search of identity and always unsure of whom they are and therefore, look for certain facilitating factors during mate selection. Some of these factors may be clearly defined while some may not. The fact remains that there is a facilitating factors which are the determinants of their selection of mates which can either be good or bad hence the problem. In our contemporary society youths and particularly adolescents no longer give room for their parents to play the traditional roles of negotiating on whom their children partner with for marriage. This also has brought about a drastic change in the family structure. Youngsters tend to choose mates for wrong reasons which need to be investigated.

Adolescents have the tenacity to deviate from social norms as a result of search of identity. This also means that the factors for mate selection if not well noted and addressed by parents and guardians as well as other relevant agencies of social change, the future of the young people will be put in jeopardy. This is because attitude imbibed by young ones tend to define and their future. With the socio-cultural changes in our society which has always brought about deviation from our culture, it is therefore necessary to examine what necessitate the choice of mate in adolescent years. 
Attitude is everything as ones attitudes affects his /her actions. It is most common for a lot of people to contradict themselves on issues relating to attitude. For instance somebody wants to get married but do not date regularly, it also relate to desiring someone who is loving, forgiving and tender but the individuals do not exhibit those same qualities on dates. Sometimes the individuals may pretend everything is fine when in fact deep down there is general feeling of unsettled mind and unhappy. These are blind spots, habits and attitudes of which one may be unaware but that dramatically shape mate selection experience (Layman, 2019). Irrespective of the aspect of soul mate that one engages in, attitude is crucial.

\section{Types of Soul Mates}

A true soul mate is a mirror, the person who is very familiar with everything that holds the other back, has the capability to bring the others to his or her attention in order to create changes in the person's life (Layman, 2019). This should be the focus of an adolescent in search of soul mate irrespective of the type adopted. Experts in social health circle have attempted to categorized soul mate in different forms. Daniji (2017), identifies five different types of soul mates that one most likely may encounter to include stranger, healing, wrecking ball, twin and true love soul mates. The stranger soul mate is someone you met randomly for example on a bus ride in an airport or simply walking down the street when you come across them. the healing soul mate is a friend who arrives with intention and they show up right when you need them the most, provide you with reliable life lessons. The wrecking ball soul mate comes into ones life when there is need for a change and the purpose is to shake things up. They challenge push and change your prospective. The twin soul mate helps one to overcome emotional and spiritual barriers. It is someone you can talk for hours with or without running out of words while the true love soul mate is the person that you will spend the rest of your life with if lucky enough to find them (Daniji, 2017). This means that a true soul mate could be regarded as a combination of other four types of soul mates.

In another report, Tanya (2020), perceives soul mate types to include: soul partner, soul ties, twin flames, soul mate friends, soul families and soul groups, kindred spirits, soul contracts, the teacher soul mate and complete stranger. According to the author, soul partners represent people that agreed to partner with in one's lifetime, soul ties refers to another soul in one's life, past-life is the type in which one feels instant familiarity at a glance Romantic is the type that come into one's life as a lover and typically take on the form of a really beautiful relationship for a period of time: soul mates friends are friends that are established at first time of contract; soul families and soul groups can show up as actual family members in one's lifetime, like a cousin who is not only part of your soul family or as people working towards common goals who never met, like activist around the globe working for a similar cause or spiritual seekers working to bring more love and awareness to planet; kindred spirits are not always a soul mate but people who understand you; soul contracts refers to agreements one makes on a soul level to do certain things in his lifetime; the teacher soul mate refers to as people who show up in your life when you are in transition or struggling with your next move and you feel this pull towards these people; the complete stranger comes in the form of a very brief encounter with somebody you don't know (Tanya, 2020). These categories of soul mates are embedded in the elements that make up the phenomenon

\section{Elements of Soul Mate.}

A soul mate makes you feel entirely whole, healed and intact like no piece is missing. In that regard, Harra (2013), outlined ten elements of soul mates to include: soul mate is something profound and lingering emotion which no words can encompass; it is a flashbacks-that is to say your partner is soul mate, chances are that he or she has been present in your post lives, you just get each other-that is soul mate connection; you fall in love with his or her flaws-that is having an easier time of accepting, even learning to love each other's imperfection; it is intense-that is to say even during negative episode you focused resolving the problem and can see beyond the bad moment; two against the world-that is seeing their relationships as "us" against the world. In other words, soul mate relationships are founded on compromise and unity above all else; you see mentally inseparable-that is having a mental connection similar to twins; you feel secure and protected-that is regardless of the gender of your partner, he or she should always make you feel secure and protected by making you feel like you have a guardian angel by your side; you cannot imagine your life without him or her that is a person you believe is worth sticking with and fighting for; you look each other in the eye-that is keeping a high level of comfort ad confidence (Harra, 2013).

Writing on the elements that make up soul mate selection Sliny (2019), included the following to the existing ones to include: your souls meet at the right time; you share the same life goals; you are not afraid of having a conversation; you do not experience jealousy; you do not scream, curse or threaten each other with divorces you know how to apologize and unconditionally; being in each other arms, washes away all your stress, worries and anxiety (Sliny, 2019). Elements of soul mate combine to make one feel entirely whole, healed and intact like no piece is missing from the puzzle. It is against this background that Hoffpost (2018), recommends ten elements guiding soul mate to include; it is something inside flashbacks, you just get each other, you fall in love with his or her flaws, it is intense, you are mentally inseparable, you feel secure and protected, you can't imagine your life without him or her and you look each other in the eyes (Hoffpost, 2018).

Understanding the various elements embedded in soul mate provide a stepping stone to greater understanding and application of the rules that guide mates selection. Consequent upon this, DeGenova, Stinnett and Stinnel (2011), recommend five rules of mate selections as follows: select mate outside your own nuclear and extended family, find a compatible person who meets your need while you can meet his /her, find someone who is good or find or maximizes your rewards while minimizing your cost, find mate with similar background, Traits, Language, religion, traditions and holidays, lifestyle and self identification workplace skills, educational aspiration and achievements, age similarity, physical appearances (skin colour, facial features and body shape and size), food preference, political learning, economic similarities common shared 
experiences (Military peace corps or other background), family cultural similarities and compatibilities, physical attractiveness similarities, hobbies and internet similarities. Life goal similarity, the $5^{\text {th }}$ rules of soul mate selection is look for warning signs of deeper problems (DeGenova, Stinnett \& Stinnel, 2011). Adolescent understanding and application of these rules may result in good selection of soul mate.

\section{Soul Mate Selection}

Finding soul mate is like finding one's other half. Spiritually, there is this general belief that even before one is born, the name of his/her spiritual half has been determine. Each soul mates has a perfect match your soul mate. There is this other assumption that most people hold which makes them think or is that when they find "the one", they just known. Call it intuition, but when soul mates find each other they know that they have met their other half (Ntianu, 2018). It has been observed that understanding each other's emotional language is crucial during mate selection. According to Ntianu (2018) everyone deals with emotion from love to anger to sadness to joy in diverse ways. For instance some people might express their love for a partner giving them a back rub, while others might express love by the dishes. The same thing applies to anger. Some people withdraw in the face of conflict while others want to talk things out immediately (Ntianu, 2018).

Soul mates might not deal with their emotions in the same way, but they understand their differences and learn to meet their partner in the middle. Many partners will find that they fight, it dissolves into a situation where both partners feel angry and misunderstood, but soul mates develop an emotional shorthand that allows both partners to be hear and get what they need (Nitinu, 2018). Many soul mates will say that the earliest soul mates signs they notice in their relationship was how comfortable they felt around each other. Even in the emotional whirlwind of falling in love, soul mates will find what they have never felt more secure opening up to someone and showing their true self. For true soul mate, the deepest levels of emotional intimacy comes more easily than either partner may have believed possible and this connection draws them to each other from the very beginning Ntianu, 2018).

A true soul mate is one who brings the other to own attentions so that the individual can change the other's life. A true soul mate is probably the most important person you will ever meet because they tear down your walls and keep you awake (Alexander, 2016). According to online report (https://www.gistmania.com/talk/topic/html), the major objective of soul mate is to shape one up, tear apart the ego a little bit, reveal obstacles around the individual and addictions, breaks the person's heart open so that new light can get in make the individual so desperate and out of control and capable of transforming the life of the person and then introduce him or her to the spiritual master. It has being observed that during mate selection, partner should rise above physical attraction while ensuring that a deep and spiritual bond exist between them (Alexander, 2016).

Research reports on adolescent mate selection criteria are not scanty in literature. A survey of medical students show that the female becoming more selective in their criteria relationship while the male were convinced that their increasing status would enable them to engage in a relationship (Townsend, 2003), A study from 36 out of 37 cultures demonstrate that financial status is an important criteria in mate selection (Badahdah \& Tiemann, 2009; Shackelford et al, 2005, Todosifvic et al, 2003). Male adolescent were more likely to prefer partner who are university undergraduate than non-graduate even though male undergraduate have shown less importance in their preferred mates to be college graduate (Koehler, 2003). This is supported by University of Iowa News Service (2009), which states that men are also increasingly interested in educated women who have good financial prospect and less interest in chastity. According to the report, in the past emphasis was on women exercising domestic skills but now men show preference for women who are intelligent and beautiful and these criteria were ranked $12^{\text {th }}$ position in 2008 as against $17^{\text {th }}$ position in 1939 (university of Iowa News Service, 2009).

It has been reported that choosing a mate with someone of lower educational background could cause challenges, while similar educational background result in similar attitude, value and behavior among mates (Malike 2009; O'Neil, 2006 $\&$ Acitelli \& Weiner, 2004). The common denominator with regard to selection of mate is that one has to find a soul mate, involve their souls in the quest for a mate and pray for God's guidance through the process. However, it is better and wiser to believe that a soul mate relationship is created..Soul mate creation needs to be identified from the onset by both partners. To this end Mceekingz (2018), identifies four things that happen when one meets his or her soul mate to include: realization of little things in life, openness to change, realization of what it means, sharing life with others and that not all relationships are the same.

\section{Soul Mate Theory}

There are designed tools to resolve issues arising from adolescents selection of soul mate. Specifically, two theories addressing the identified problems of the study anchored the study namely: the Social Exchange Theory and Stimulus Value - Role Theory

\section{The Social Exchange Theory}

The social exchange theory was propounded by Thibaut and Kelly in 1959. The theory states that people form and dissolve social relationships according to costs and benefits. That is to say one forms a relationship with someone who offers higher rewards and lower costs. The theory is based on the assumption that in social relationship people are faced with rewards which they can get from the other and cost which they suffer. Possible rewards in the relationships are help and 
social support, so that one reward can be willingness to provide these. From the context of the theory, if no relationship offers this minimum level of rewards-cost difference, it means that individual's best choice is to be alone. In addition, the higher the rewards - costs difference over the comparison level (CL) is- the more satisfactory is the reward-cost difference in the actual relationship, the person will leave the relationship for another one. Similarly if adolescents should have preference for similarity, no such exchange would be possible. This also implies that a man with high status and earnings could exchange that with a woman of great physical beauty.

\section{Stimulus Value-Role Theory}

This theory was propounded by Bernard Mustein in the early 1970s. The theory states that exchange is mutual and dependent upon the subjective assets and liabilities each individual brings to the relationships. The stimulus is the traits (usually physical) that draws attention to the person. After a couple of dates, value (nothing of what is desirable or undesirable) are compared for compatibility and an evaluation of the costs is calculated. If after time and relational compatibility supports it, the pair may choose to take roles (being a boyfriend or wife) which typically includes: exclusive dating, cohabitation, arrangement or marriage. These theories could provide additional understanding about mate selection including the benefits that could be derived from it.

\section{Benefits of Soul Mate.}

Getting the right soul mate is like someone being complete due to the benefits that could be derived from it. Miliki (2019), identified the following benefits that could be derived from choosing a mate to include: having a feeling of mental insatiable, having the feelings of security and protection, falling in love with his or her flaws, having the capabilities to hear the other person's silent thoughts, feeling each other's pain. These benefits sometimes could differ with individuals depending on his or her preferred choices regarding soul mates. Other observed benefits of healthy soul mate selection include: knowing each other's flaws and the benefits in them, sharing the same life goals, not being afraid of having a conversation, not threatened by the need for alone time, mates do not experience jealousy and respect each other's differences and opinions (Tiemann, 2019).Sometimes the perceived benefits of soul mate particularly among adolescents could be the major factors to mate selection.

\section{Determinants of Mate Selection}

Selecting a mate is perhaps one of the most serious and challenging decisions that adolescents face in the course of their growth and development in life. The preference to soul mate sometimes could vary from individual to individual and guided by several factors. One of such factors is occupation status. Todosejvic, Lyubinkovic and Avranie (2013), have looked at occupation status embodied by clothing and attractiveness on female willingness to engage in romantic relationship. Male targets were pre-rated for physical attraction and come in to two categories, handsome and homely. The targets were one of these three costumes blazer shirt, designer tie and conspicuous. Rolex Watch. They were described as being doctors (high status). Plain white shirts: they were described as being teacher (medium status). Uniform of a Burger King employee: They were described as being trainee waiter (low status) (Todosejvic et al, 2003)

Females state their willingness to engage in relationships with the men at six levels of romantic involvement, the high status males were preferred to low status males at all six levels and status were more important than attractiveness. Women who are high status themselves also prefer males of high status preferably of even higher status than themselves (Badahdah \& Timann, 2009). A survey of medical students found females becoming more selective in their criteria in entering a relationship while the males were convinced that their increasing status would enable them to engage in a relationship (Todosejvic et al, 2003). From the expert opinions among various characteristics of desired mates, physical attractiveness and appearance are most dominant traits.

Socially, studies highlighting age similarity as a factor considered important especially by civilized class. The assumption is that individuals of same age have same level of understanding and exposure to the world (Glenn \& Marquardt, 2011), Age similarity also enhances emotional satisfaction of partners maintaining kindness and understanding, intelligence and an exciting personality (Glenn \& Margguardt, 2011). The adolescent age bracket according to WHO (2015), is 11-19 years. It has been observed that majority of students would prefer to be in a relationship with someone with the same or similar educational achievement and family background (Suaver, 2015). The social factors sometimes alongside with sociocultural and religious factors may be the guiding principles to soul mate selection.

Experts have reported certain socio-cultural determinants of soul mate selection. Studies on socio-cultural correlates of mate stability observed that individuals religiosity (measured in a variety of ways) tends to negatively associated with occurrence of mate separation. Focusing primarily on religious service attendance as an indicator of religious commitment, a non significant relationship between attendance and separation (Mahoney, 2010). This point to the fact that religious ideology is associated with less antagonism between mates. Culture influence the formation of focal relationships as well as the relative importance of subsidiary relations that constitute the map of the network of relationships involved in a project (Abosag, Tynan \& Lewis, 2012).

Some people focus on the inherited characteristics (physical attributes) before making choices with respect to mate. Physical characteristics refers to the features such as hairstyle, facial features, body frame, colour, shape of nose mouth and 
other body areas that are visible to the eye. Physical characteristics are defining traits or features about one's body. (Stephen, Hiew, Coetze Tiddeman \& Perrett, 2017). Other physical attributes that shape the choice of mate includes plump, stocky, overweight, fat, medium build, athletic, slender, lanky, fitness, slim, muscular well built. It also involve assessing how tall or short the person, skin tone and complexion, hair colour and texture (Kanazawa, 2011). The physical attributes of a mate may not necessarily be the only focus but also the socio-economic status of the mate.

Socio-economic status relates to lifestyle component and measurements of both financial viability and social standing. Sociologists investigating social privilege and levels of financial independence in terms of how they affects human behaviors and circumstance observe a significant correlation of them to pattern of drug use, food choices, migration, diseases prevalence and rates of mortality in human populations (Kalmijn \& Flap 2019). The economic status of an individual depends on the type of occupation that one is engaged in. The occupation factors could be the focus of some individuals during mate selection. Mate survey on women demonstrated consistent women expression of preferences for partners who have high status profession. The report attributes the disposition to the tendency for women to place high value on men who possess a promising career orientation, industriousness and ambition (Kalmijn \& Flap, 2019). This perhaps suggests that women are more significantly likely to discontinue relationship with males who become unemployed, lack career motivation or show laziness. The occupation of the prospective mate is often evaluated by the parents of both mates.

Parental influence plays a significant role in mate selection in most societies. Mate selection patterns of the Kipsigns, a pastoral group in Kenya is technically made by the young woman Kin, but in most cases the parents decisions are influenced by their daughter's choices. These joint decisions are strongly influenced by the amount of land made available to her and her future children. In this society just like the Hausa/Fulani tribes of Nigeria, land and cattle are controlled by man and gaining access to these resources has important reproduction success. This may be an important causal factor contributing to reproductive differentials, given the greater availability of food in the homes of "richer" women and the lower incidence of illness among them and their offsprings (Borgerhoff, 2008). In the Kenya experience, land is divided among her son who eventually uses the land to attract wives. Women who gain access to large plots of land (through marriage) have more surviving grandchildren than do women with small land plots (Borgerhoff, 2008). Usually parental influences are greatest when the parents have a large stake in who their child mate with. The most extreme form of parents influence is an arranged relationship in which the prospective bride and groom have no say at all as evidenced in Chinese culture in which both mates meet for the first time on the wedding day (Mike, 2014). Total dependence on parental standards could result in wrong choice of soul mate and portends great dangers to mate selection.

\section{Consequences of Wrong Choice of Soul mate}

Adolescent soul mate selection is a growing phenomenon across the globe and is generally recognized public health issues and an economic perspective. A wrong choice of mate selection could result in adverse consequences for both sexes. Notable social and health consequences of mate selection include prostitution, medical problems and suicide (Bamgbose, 2012; Women Aid Collective-WACOL, 2015). Other reported consequences of wrong mate selection include expecting problems to work themselves out ending great relationship, pushing your friends and family away, missing out on great opportunities, putting one's life on hold, forgetting to establish boundaries, missing red flags and feeling let down (Hamid, 2011). Furman (2002), states that adolescent are mostly prone to problem adjustment when they get involved in relationship at early stage of life.

Adolescent engagement in mate could result in certain health risks and even death related premature forced sex and early pregnancies. They are also at increased risk of HIV and other sexually transmitted diseases (United Nations Population Fund, 2018).The existence of these consequences is a call to action. Human kinetic and Health Education perceptions and interpretations of factors to soul mate selection could provide a useful guide to adolescents in search of mates.

\section{Human Kinetics and Health Perceptions and Interpretations of Soul Mate Selection}

Human kinetics is an aspect of general education process aimed at the development of physical, mentally, emotionally and socially fit citizens through the medium of physical activities that have been selected with a view to realizing these outcomes. The general objective of kinetics is to understand factors that enable and limit an individual's ability and its effects on the individual and the society. Health on the other hand is of different dimensions which determine the wellbeing of individual and communities. Some of the dimensions include: health is personal, that is hereditary determines the state of an individual wellness for example, colour of skin, height, weight and some other traits in humans are hereditary. Health is an ability to recover and bounce back from illness and other problems (Idowu, 2019). Health education therefore, is an educational process that teaches people about health; that covers physical, social, emotional, intellectual and spiritual health. The whole essence of health education is to preserve, promote and maintain health (Oladipupo, 2019). These two disciplines kinetics and health education from their objectives perceive and interpret mate selections in that regards. For instance, a partner is required to be physically fit and healthy and gives the mate the confidence about protection and longevity.

A woman's goal during mate selection is to have a man who can support her financially on the assumption that such a union may result in setting up a family with good health standing hence the adage "health is wealth or wealth is health". In that regard, women often choose their males based on the ability to provide a high level of parental investment and what men will be able to prove for the offspring when the child is born (Georg \& Hancore, 2012). This view is supported by Myers (2010), report which states that human are social animal and long for intimate relationship in which love can be given 
and received freely (need to belong theory). To this end Roman (2010), subunits that getting involved in relationship come with physical contact which causes chemical to gain love and confidence in them. Sporting activities give people opportunity to get involve in relationship and the physical body contact could also trigger arousal to gain love.

Men more than women, regardless of cultural background tend to seek for physical attractive younger mates. The issue of aesthetics is one of the cardinal objectives of human kinetics-that is maintaining appropriate body form that is appealing (Geary Vigil \& Byrd Craven, 2004). This view is supported by Maliki (2009), observations that male targets were pre-related for physical attraction and divided into two; handsomeness and homely which relate to aesthetics and beauty that are highly emphasized in health and kinetics.

Religion has become an important criteria for selecting mates, Maliki (2009) and Furmam (2002), in their separated reports state that religious and political powerful relate to individual values and belief and recommend that potentials males should have religious beliefs. Similar religious ideology is associated with less antagonism between mates (Badahdah \& Tiemann, 2009). Spiritual wellbeing and cohesion are strong indices of health. This is so because humans have belief in a higher power which conquers existential loneliness and despair (Idowu, 2019). This rightly explains the argument put forward that spiritual wellbeing is the most vital as it has an overriding sense of meaning and purpose in life. Spiritual health is central to an individual's happiness and wellbeing also makes an important contribution to economics progress for a healthy population like longer is more productive and actualizes more (WHO, 2019),

\section{Conclusions}

Soul mate choice is a matter of destiny. It is not some single already determined end to life that is yet to be believed. It is rather the end you get after certain actions have been carried out. For example a properly cooked pot of soup is destined to taste good if salt is added and destined not to taste so good if not added. In other words your actions determine the destiny instead of the "it will happen no matter what you do" notion so many people like whether you add salt or not the soup will taste good or bad. It is pertinent to note that neither you are designed by the universe to be soul mates or two loving people who have settled for each other's strengths nor weakness, the decision is yours. The beauty of free will is that you can remain in or change any relationship as you deem it fut. To be with your soul mate is one of the precious treasure of life. If you feel you have found your endless days of joy and laughter and countless nights of deep embrace, unraveling the mysteries of the universe one by one (Natasha, 2011).

\section{Suggestions} adolescence

Arising from the conclusions of the study, the following recommendations are made regarding mate selection in

1. Mate selection should be based on the principles of social exchange between both sexes for the purposes of mutual thrust and respect.

2. As vital as the institution of soul mate is, it requires adequate preparation and prospective mates should be subjected to proper counseling and training as we do when entering new employment.

3. The issue of soul mate should be made a priority among adolescents especially students in the university in view of the growing cases of rape in Nigeria today. This should be encompassing and would be an exceptional way to develop life skills in adolescents.

4. Adolescents should select mate on the basis health and sustenance of health. There should be clearly defined prospect of economic stability.

5. Mate selection should be based on socio-cultural and religious affinity of both partners. This may ensure heavenly connection which is an important aspect of health and wellbeing.

6. Physical characteristics and other traits are necessary in a mate in order to recreate one's hereditary defects. For example a lady that is short should look for a man that is average in height or tall.

7. Parental and other confidants could be involved in the process of mate selection on advisory note while the final decision lies with the individual.

8. Above all, attitude which is ranked highest on the basis of personality assessment should be the major focus in adolescent mate selection.

\section{References}

Abosag, I., Tynan, C. \& Lewis, C., (2012). Relationship Marketing: The Interaction of Cultural Value Dimensions. Academy of Marketing Annual Conference, Nottingham Business School.

Alexander, S.M., (2016). Should you look for a soul mate- or create one. Available on https://www.bahaitteaching .org/looksoul-mate-create-one/. Retrieved on 28th March, 2020.

Badahdah, A. M. \& Tiemann, K. A., (2009). Religion and mate selection through cyberspace: A case study of Preferences among Muslims, Journal of Muslim Minority Affairs, 29(1): 83-90.

Badahdah, L. \& Timann, D., (2019). The Social Physiology of Groups. New York, John Wiley and Sons Incorporated. 
Bamgbose, O. (2012). "Customary Law Practices and Violence against Women: The position Under the Nigerian Legal System". Paper presented at $8^{\text {th }}$ International Interdisciplinary Congress on Women hosted by Department of Women and gender studies, University of Makerere, Uganda.

Bereezkei, T. \& Csanaky, A., (2006). "Mate Choice, Marital Success and Reproduction in a Modern Society”. Ethology and Sociobiology, 17:17-35.

Bogerhoff-Mulder, M., (2008). “Kipsigns Bridewealth Payments” In Bretzig, M., Bogerhoff-Mulder \& P. Turke (eds.). Human reproductive behaviour. A Darwinian perspective (pp.65-82). Cambridge, England: Cambridge University Press.

British Broadcasting Corporation (BBC), $7^{\text {th }}$ February, (2012). "Nigerian Girls Sues Over Forced Marriage", Accessed September 6, 2012.

Daniji, E., (2017). Differenttypes of soul mates youwill encounter in your life. Available on www.citypeopleonline.com/5different-types-of -soul-mates-will-encounter-life/. Retrieved on 28th March, 2020.

DeGenova M.K., Stinnett, N., \& Stinnet. N., (2011). Intimate relationships, marriages and families (8 ${ }^{\text {th }}$ edition) New York: McGraw-Hills.

Fasoranti, O. O. \& Owagbemi, G. O., (2012). Strains in family values in a Yoruba community: A study of families in Akoko Land in Ondo State. European Scientific Journal, 8(26): 160-171.

Fisher, J., (20160. The Ideal Man: An Investigation into Qualities that Influence Mate Selection Among Female Undergraduate Students. International Journal of Business, Humanities and Technology. 3(1): 80-84.

Geary, D. C., Vigil, J. \& Byrd Craven, J., (2004). Evolution of human mate choices. Journal of Sex Research, 41(1): 27-42.

George, J., Hancock, D, (2002). Where is the money honey? The socioeconomic effects of mate choices. Available on https://www.feedwasmaps.com. Retrieved on 10th April, 2020.

Glenn, N., \& Marquardt, E., (2011). Hooking up, hanging out and hoping for Mr. Right: College women on doing and mating today. USA Independent Women's Forum.

Greenlees, I. A. \& McGrew, W. C., (2004). Sex and Age Differnces and Tactices of Mate Attraction: Analysis of Public Advertisments: Ethology and Sociobiology, 15: 59-72.

Hamid, I., (2011). Marriage, decision making, spousal communication and reproductive health among married youths in Pakistan. Global health action, 4, 10.

Harra, C., (2013). The 10 elements of a soul mate. Available on https://www.hufffpost.com/elements-of-a-soul mate. Retrieved on 8th April, 2020.

Hatfield, E. \& Sprecher, S., (2015). Men's and women's preferences in marital patterns in the United States, Russia and Japan. Journal of Cross Cultural Psychology, 26:728-750.

Idowu, B. B., (2019). Sexuality: The Savour, the Caution, the Pleasure. Lagos State University Inaugural Lecture series 69th Edition, LASU, Ojo, Lagos.

Kalmijn, M. \& Flap, I. D., (2019). Assortative meeting and mating: Unintended consequences of organized settings for partner choices. Social Forces, 79(4):1311-1312.

Kanazawa, S., (2011). "Intelligence and physical attractiveness". Intelligence, 39(1):7-8.

Lyman, B., (2019). Why you have to be the one to find the one. Available on https://www.chabad.org/thejewishwomen/article.cdo/aid/1685809/jewish/woman. Retrieved on 26th March, 2020.

Mahoney, T. Y., (2010). Perception of early marriage and future educational goals attainment for Hmong female adolescents. Menomonie Wisconsin, University of Wisconsin-Stout.

Maliki, A. E., (2019). Determinants of Mate Selection Choices Among University Students in South-South Zone of Nigeria. Edo Journal of Counseling 2(2):165-174.

Mark, T. S. \& Elizabeth, F. K., (2017). The Ascended Masters on Soul Mates and Twin Flames. Initiation by the Great White Brotherhood: Summit University Press.

Mceekvingz, A., (2018). Four things that only happen when you meet your soul mate. Acailable on https://www.festnesplay.com.ng-happen-when-you-meet-your-soul-mate. Retrieved on 25th April, 2020.

Natasha, G., (2011). Do you believe in karma? Soul mates? Destiny? Available on https://www.nairaland.com/6826017/believe-karma-soul-mates-destiny. Retrieved on 8th April, 2020.

Ntianu, O., (2018). How do you know when you have found your soul mate? Available on https://www.pulse/lifestyle/relationships/weddings/relationship-advice. Retrieved on 28th March, 2020.

O’Neil, D., (2016). Sex and marriage: An introduction to cultural rules regulating sexual access and marriage. Paloman College, California.

Oda, R., (2011). "Sexual Dimorphic Mate Prefrences in Japan: An Analysis of Lonely Hearts Advertisments". Human Nature, 12:191-206.

Ogunjuyigbe, P. O. \& Adewumi, E. O., (2003). Mate selection and marital fertility: The case of Yorubas in the rural areas. Anthropologist, 5(1):9-15. 
Oladipupo, B. O., (2019). Goodie bag of Health problems: Health educator the town crier. Lagos State University Inaugural Lecture series 71st Edition, LASU, Ojo, Lagos.

Owagbemi, G. O. \& Maduawuchi, E., (2015). Appraisal of factors facilitating mate selection among university undergraduates in Ondo State, Nigeria. European Journal of Research in Social Sciences, 3(4):55-57.

Patrick, H., (2012): Collins English Dictionary: William Collins Sons \& Co Ltd., p1390.

Population Council, (2015). Project Nigeria Addressing Child Marriage in Northern Nigeria, Accessed on February 5, 2015.

Sliny, J., (2019). 18 signs you have found your soul mate. Available on https://www.lifeback.org/articles/communication/18signs-you-have-found-your-soul-mate. Retrieved on 5th April, 2020.

Springer, S., (2012). Soul Mates do exist, Just Not in the Way We Usually Think”. Psychology Today, 2(1):10-17.

Stephen, I. D., Hiew, V., Coetzee, V., Tiddeman, B. P. \& Perrett,D. I., (2017). Facial Shape Analysis Identifies Valid Cues to Aspects os physiological Health in Caucasian, Asian and African Populations". Frontiers in Psychology, 8(1):18831889.

Suaver, S., (2015). Universal dimensions of human mate preferences: Personality an Individual Differences, 39(2):457-458.

Thiabaut, J. W. \& Kelly, H. H., (1959). The Social Psychology of Groups. New York, John Wiley and Sons Incorporated.

Todoseyvic, B., Ljubinkovic, S. \& Arancic A., (2003). Mate selection criteria. A trait desirability assessment study of sex differences in Serbia. Evolutional Psychology, I. 116-126.

Todosijievic, B., Ijubinkovic, S. R., (2003). Mate selection criteria: A trait desirability assessment study of sex differences in Serbia. Evolutionary Psychology, 1:116-126.

Townsend, J.M., (2003). Sexuality and partner selection: Sex differences among college students. Ethology and Sociobiology, 14(2):305-330.

UNICEF, (2015). The State of the World's Children, 2015, Accessed 22 ${ }^{\text {nd }}$ February, 2015.

United Nations Population Fund, (2018). Child marriage Online. Available from https://www.unfp.org, Retrieved on $24^{\text {th }}$ October, 2018.

World Health Organization, (2019). World health report on world health day. Philadelphia: WHO Publications. 